\title{
Caderno de Fotografias
}

\section{Fragmentos visuais do som}

Imagens do acervo de instrumentos musicais do Ethnologisches Museum de Berlim.

Diante da grande quantidade de instrumentos musicais que se encontram nas salas do acervo de etnomusicologia do Museu Etnográfico de Berlim, as fotos deste caderno não poderiam documentar toda esta riqueza, mas sugerem que o olhar quase que intruso do visitante logo se prenda a detalhes dos instrumentos. A variedade de materiais, de cores, de formas, de superfícies e de acabamentos, corresponde também à grande variedade de timbres e de músicas outrora produzidos por estes instrumentos, centenários, muitos deles, com poucas décadas ou anos os outros. Como estão mudos, confinados em salas hermeticamente fechadas do museu, faltando-lhes o elemento humano, e portanto o som, a busca do olho por detalhes nestes instrumentos parece querer suplantar a falta sonora captando os seus detalhes visuais. Desta forma o olho reconhece, o que o ouvido já sabe: além de representarem diferentes e sofisticadas técnicas de construção, instrumentos musicais simbolizam uma percepção de mundo, que tem no elemento sonoro a sua mais completa tradução.

Nota: Agradecemos ao diretor do Departamento de Etnomusicologia do Museu de Berlim, Prof. Artur Simon, por ter dado acesso ao acervo de instrumentos, cujo ensaio fotográfico se publica pela primeira vez neste caderno de fotografias.

Fotos: Tiago de Oliveira Pinto 


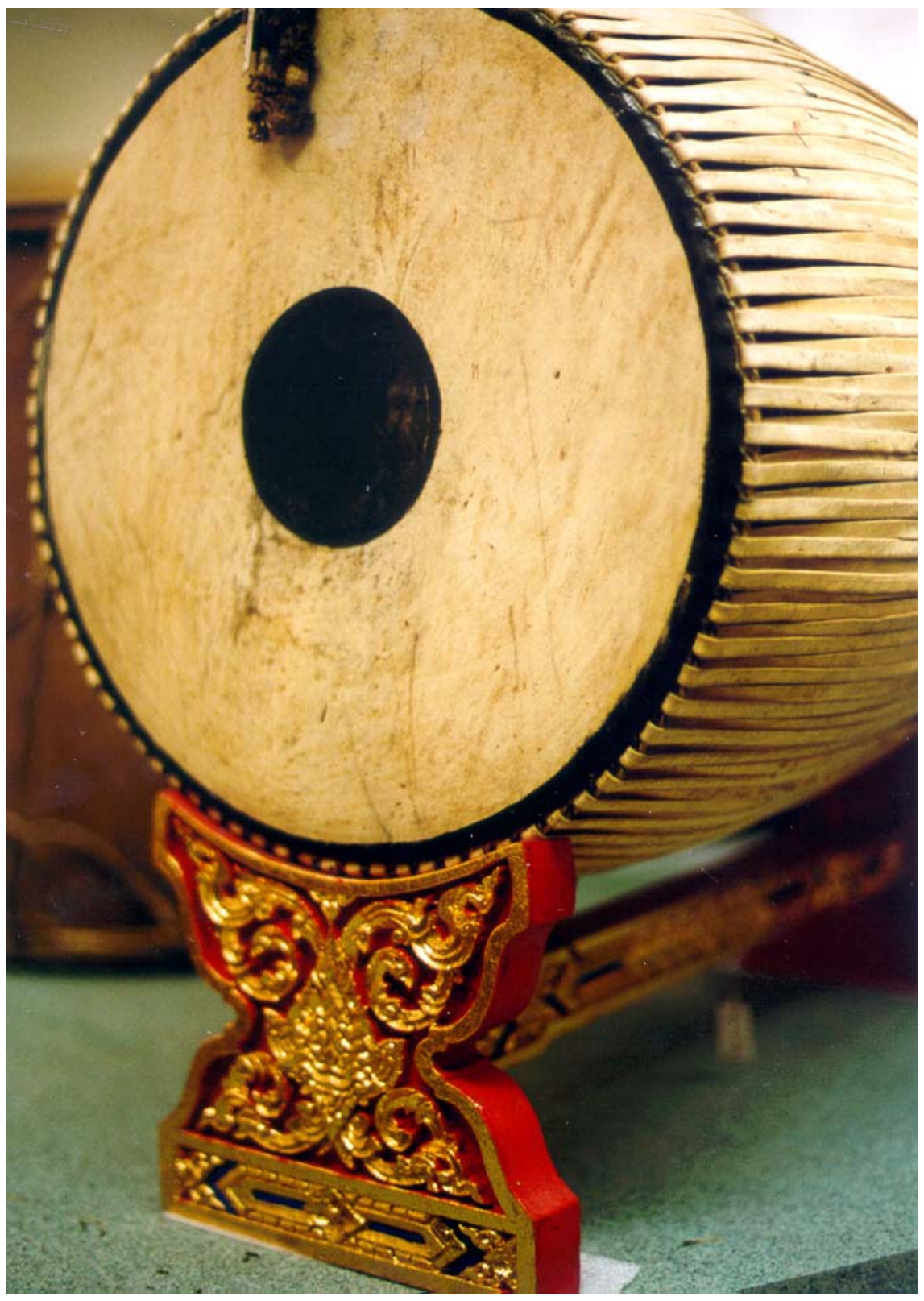




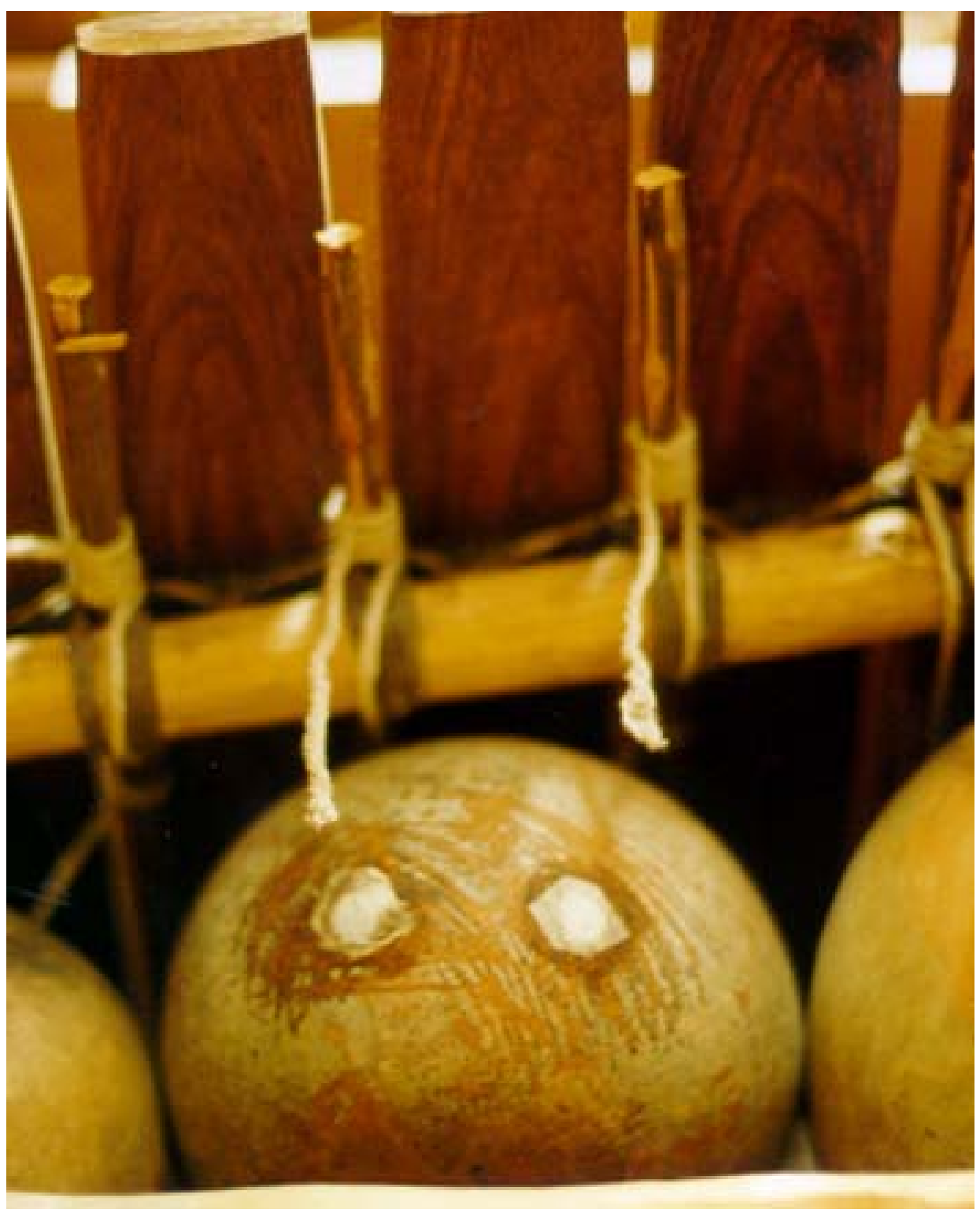



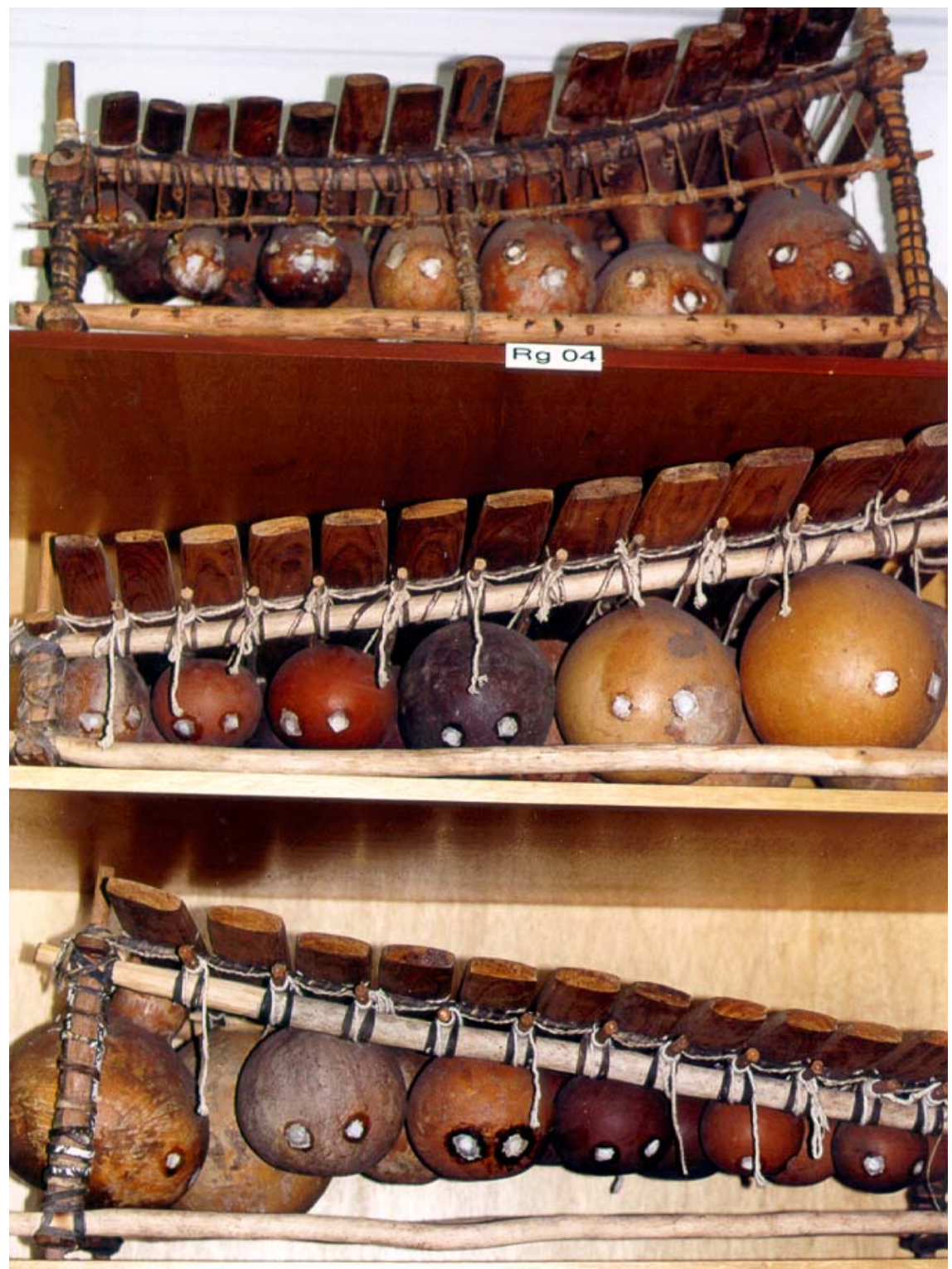


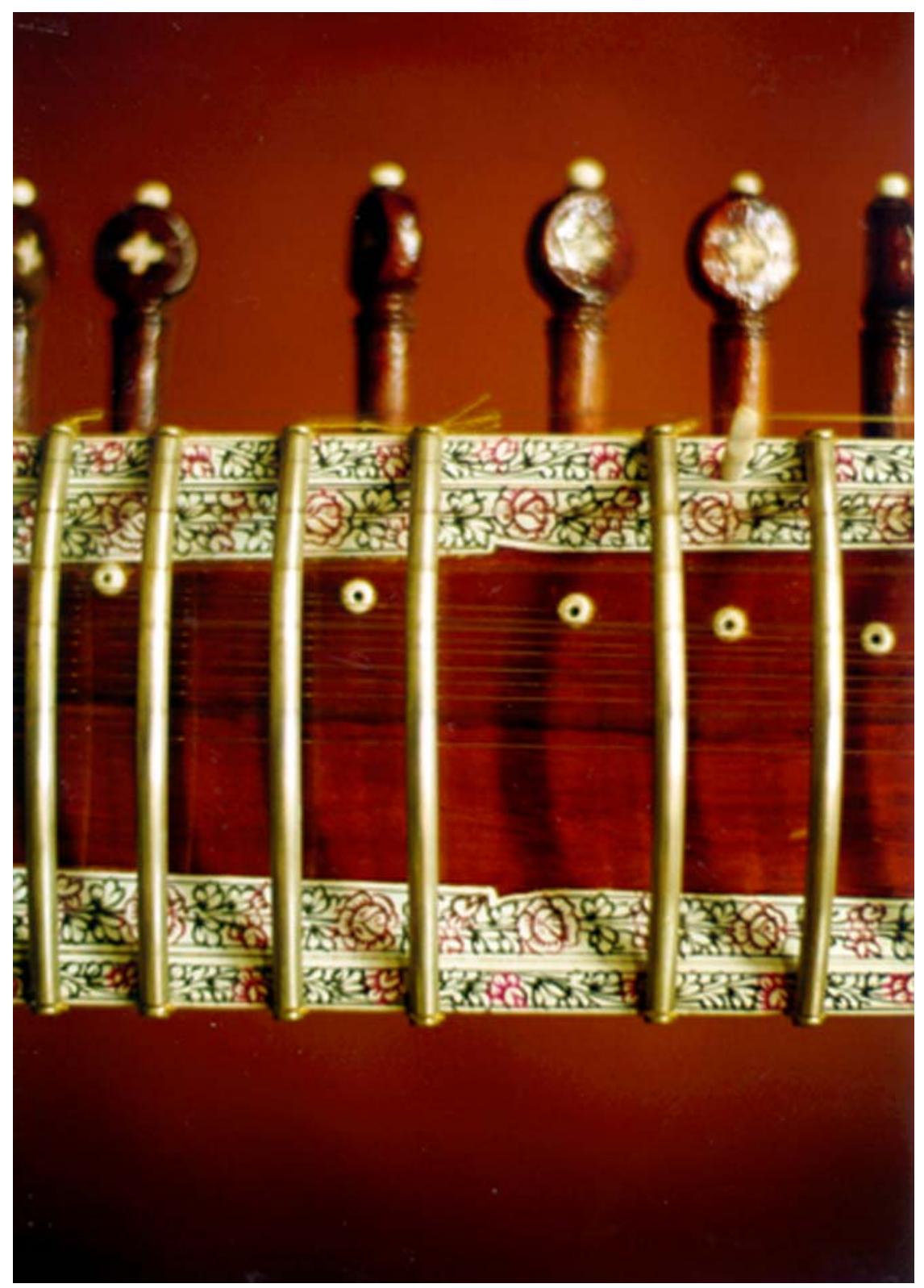




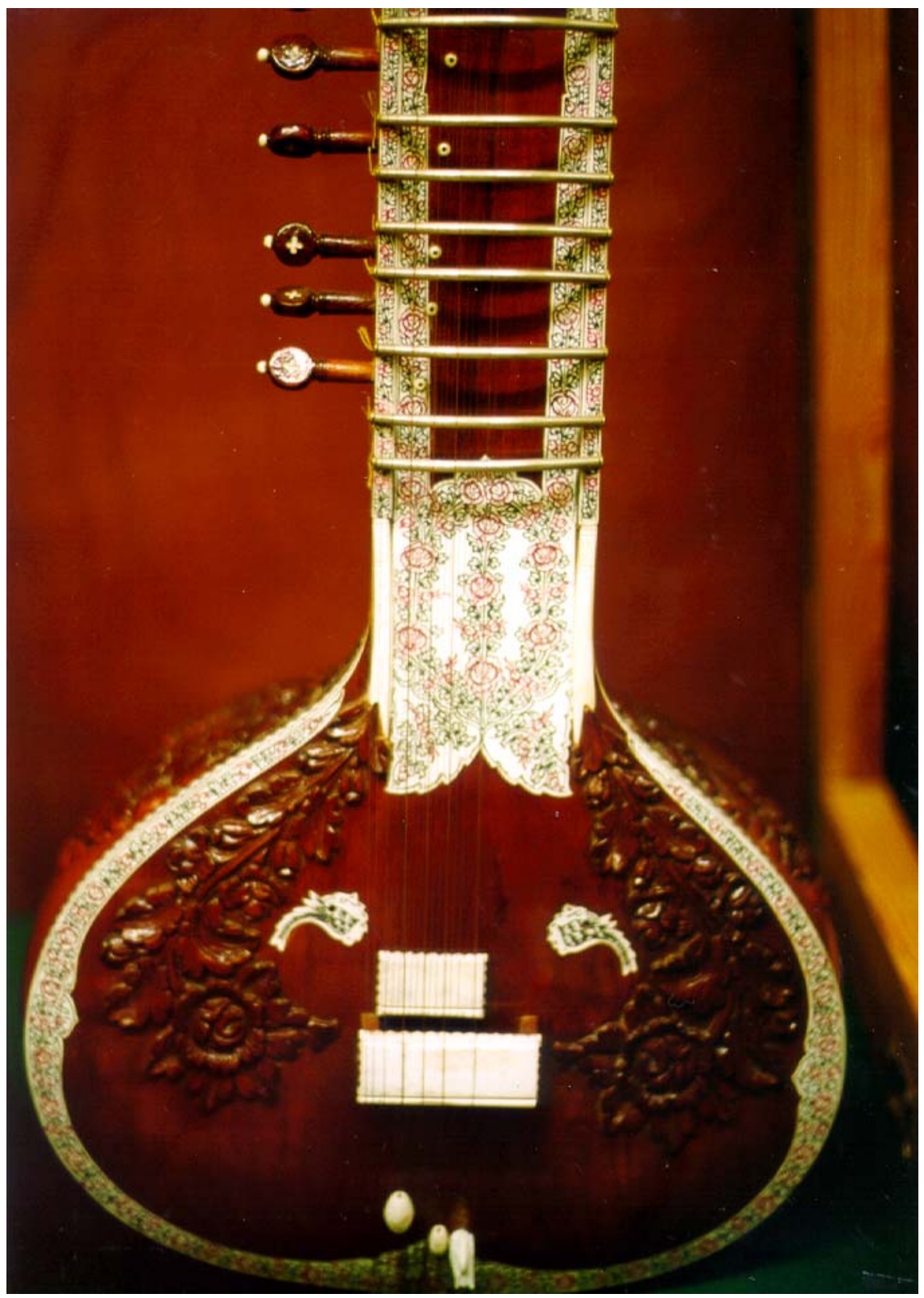




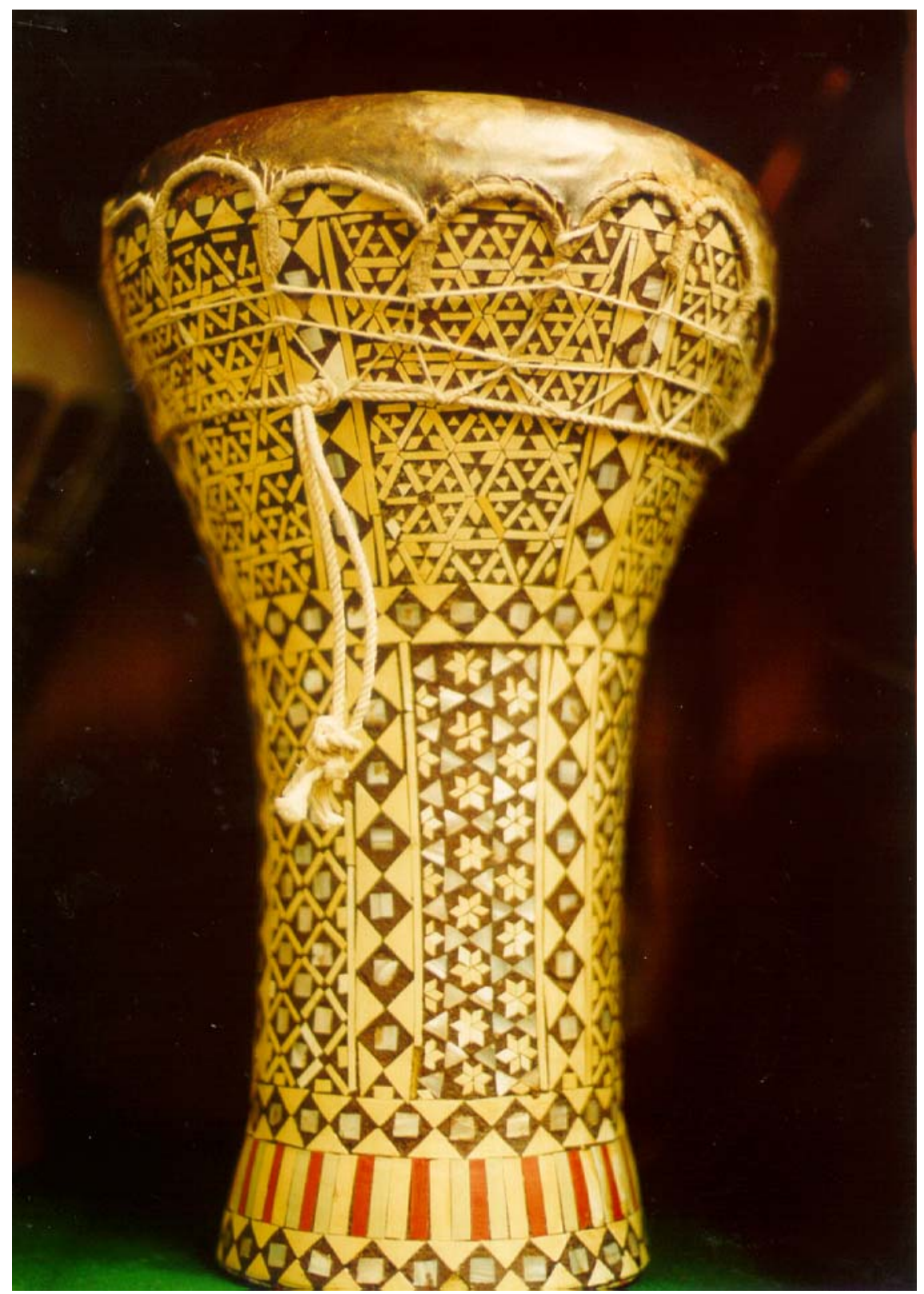




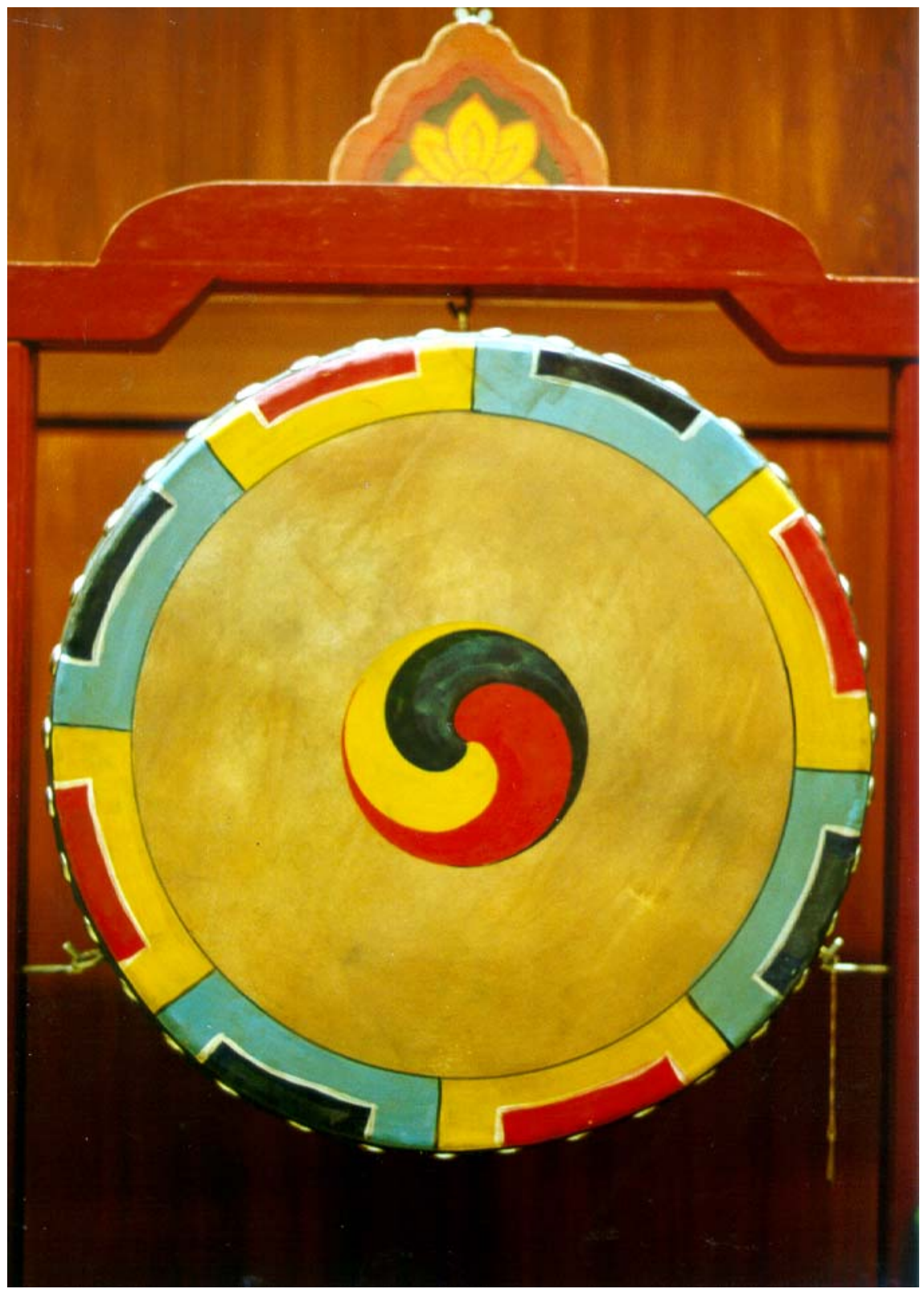




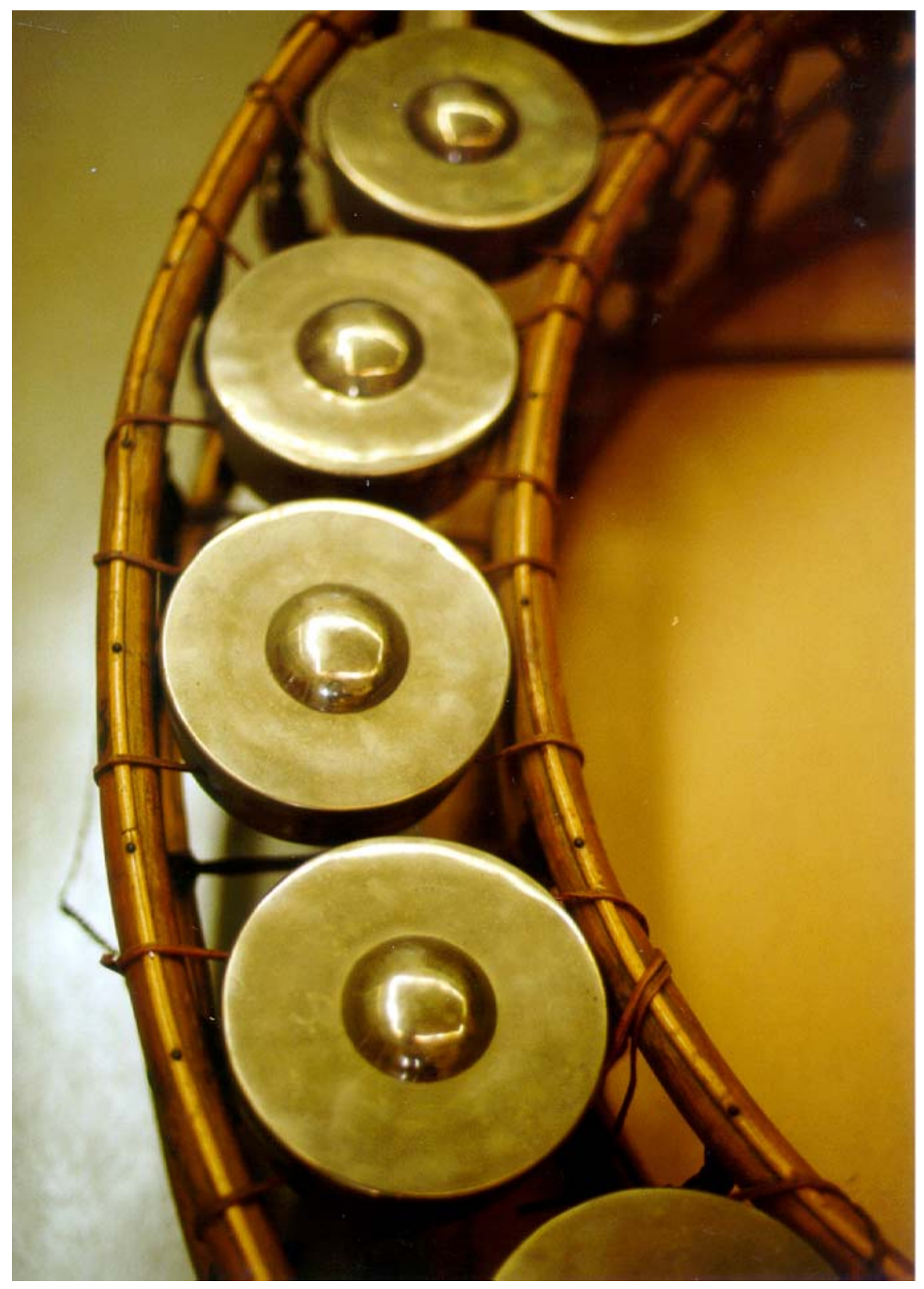




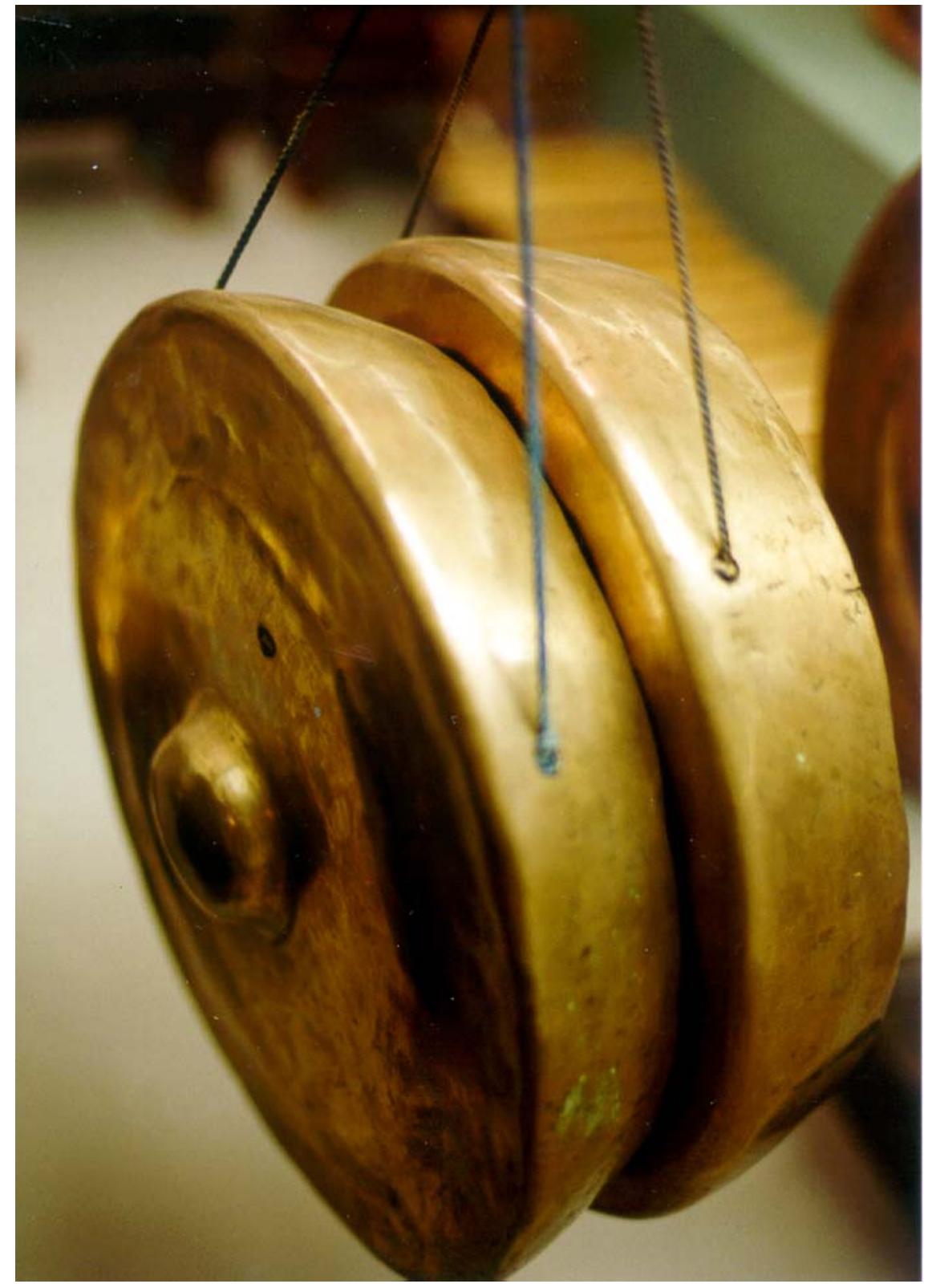



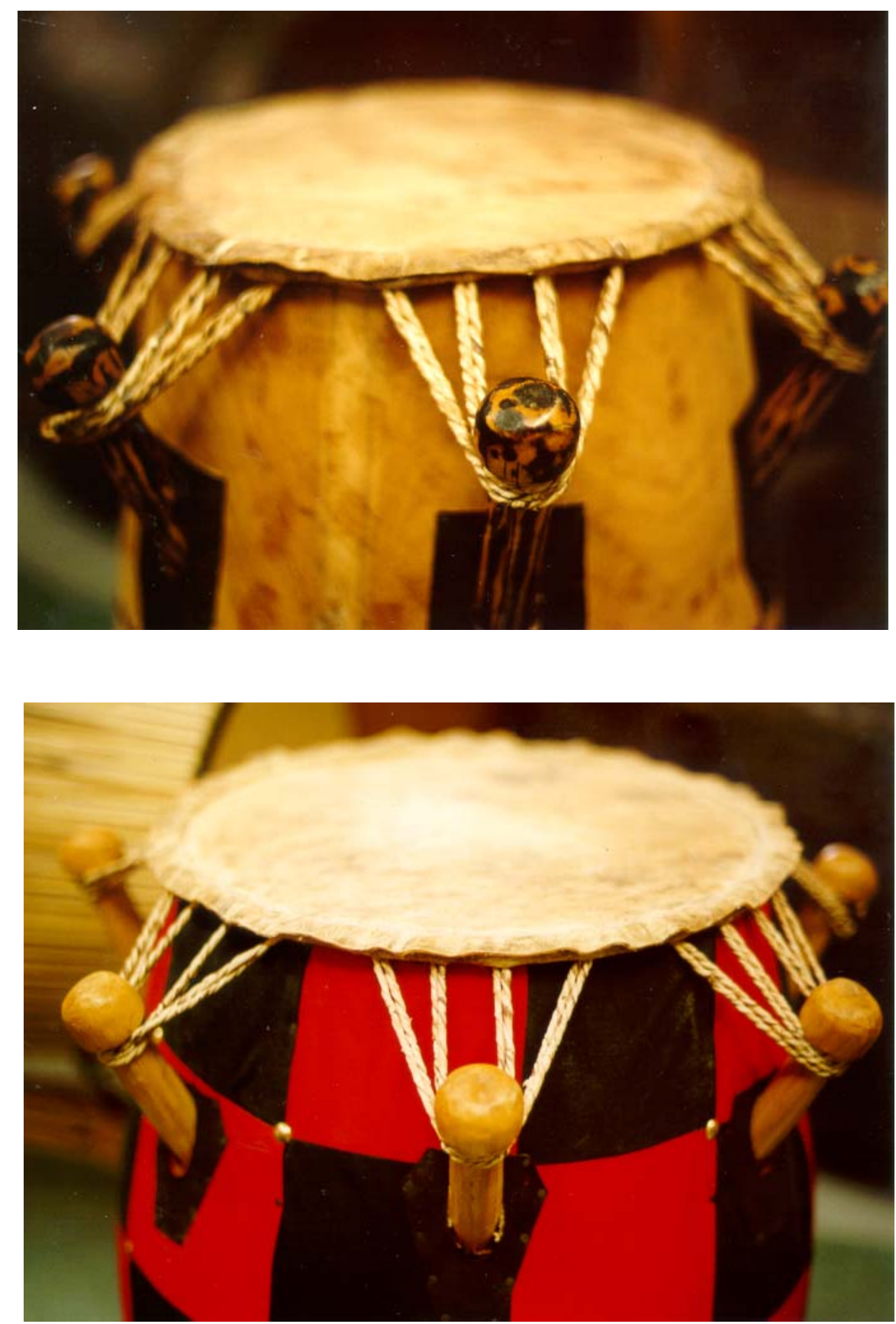


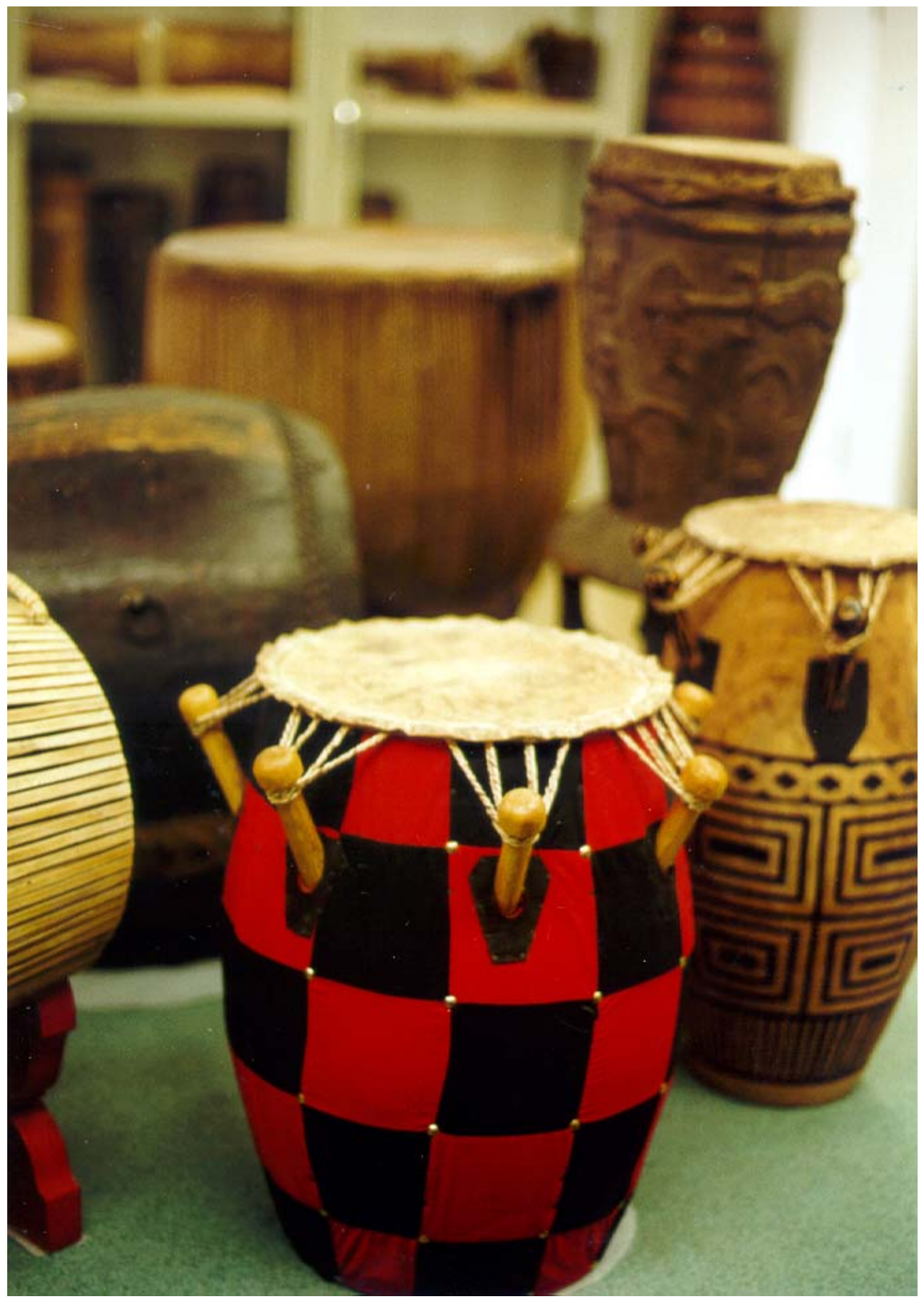




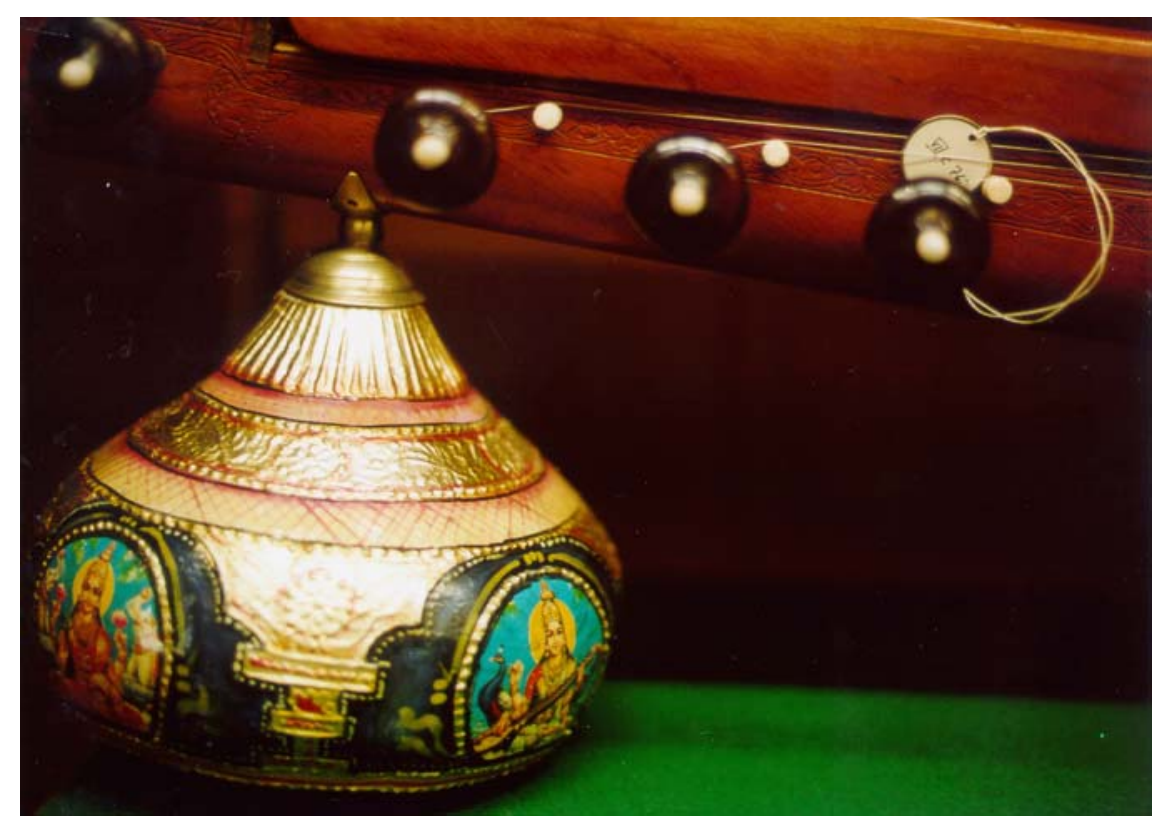




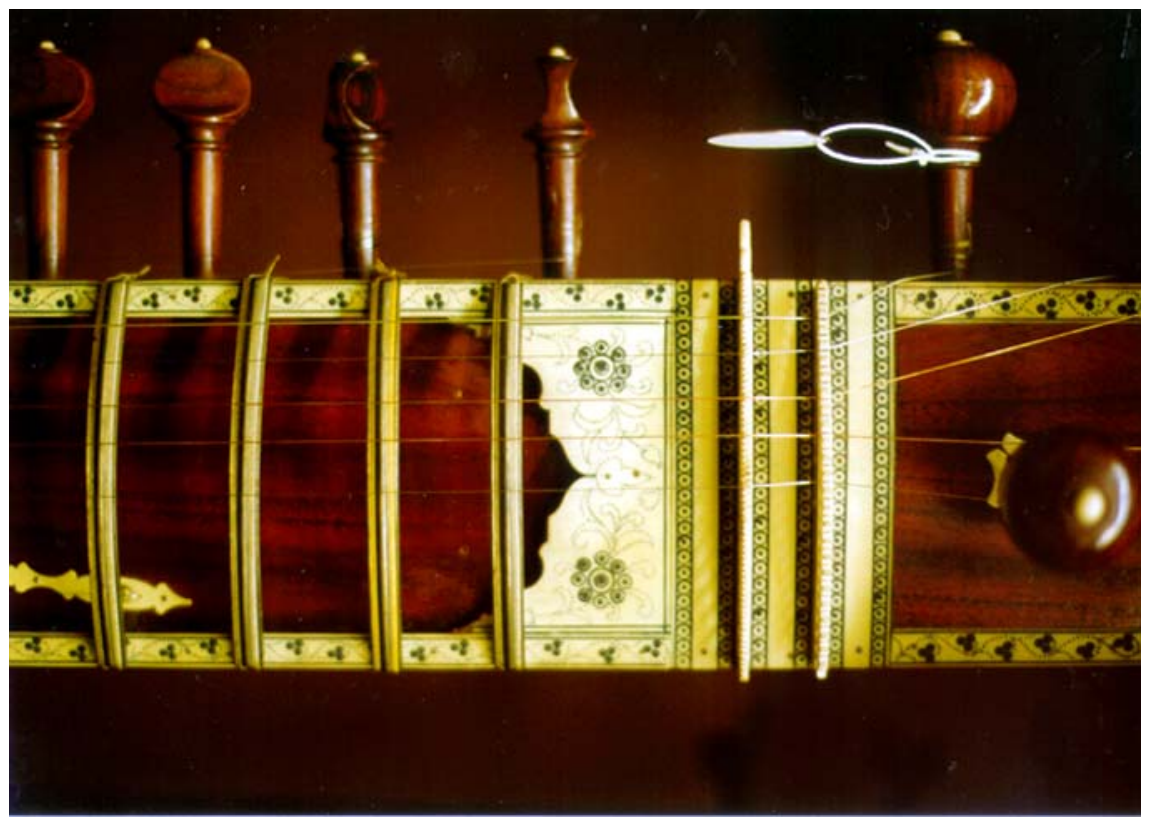




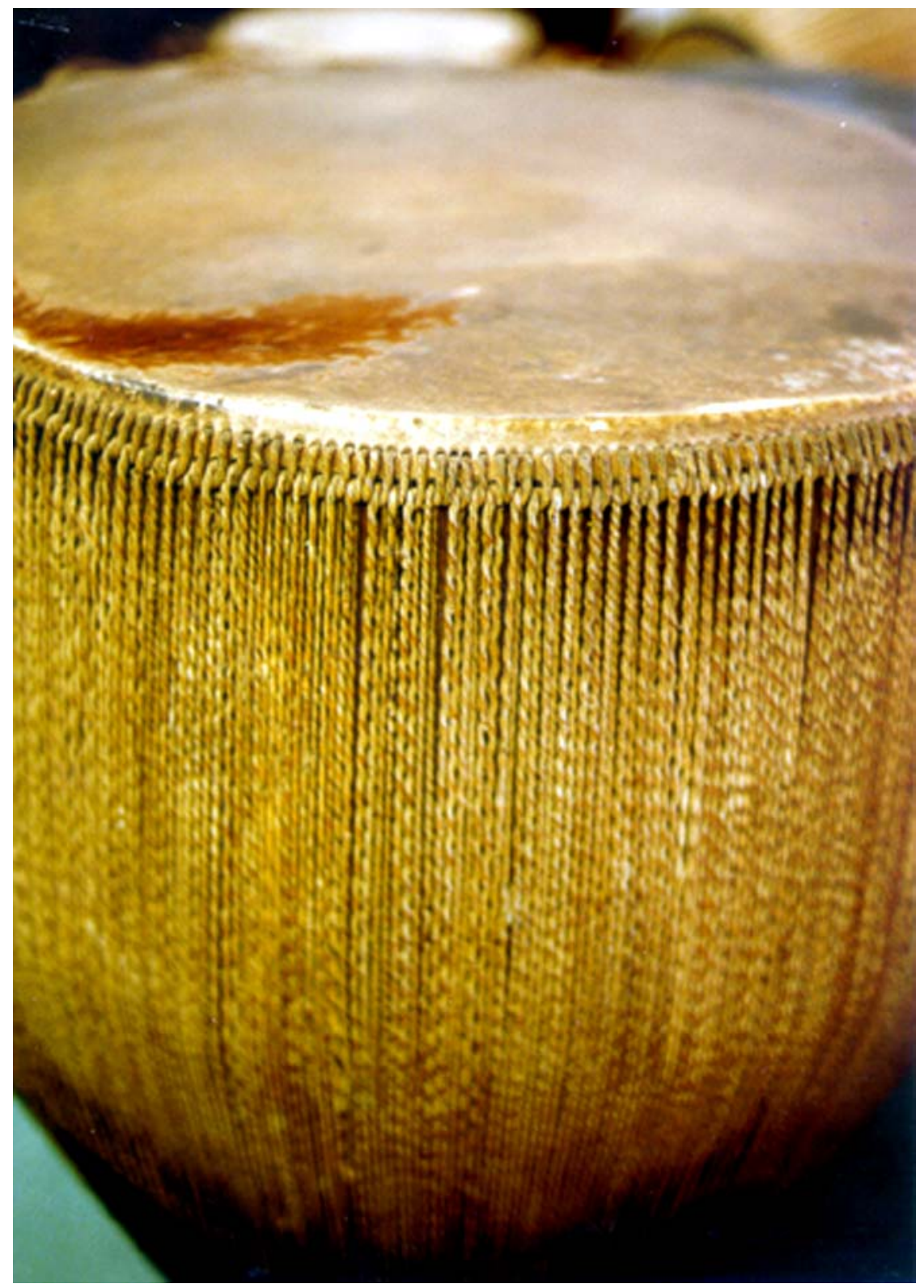




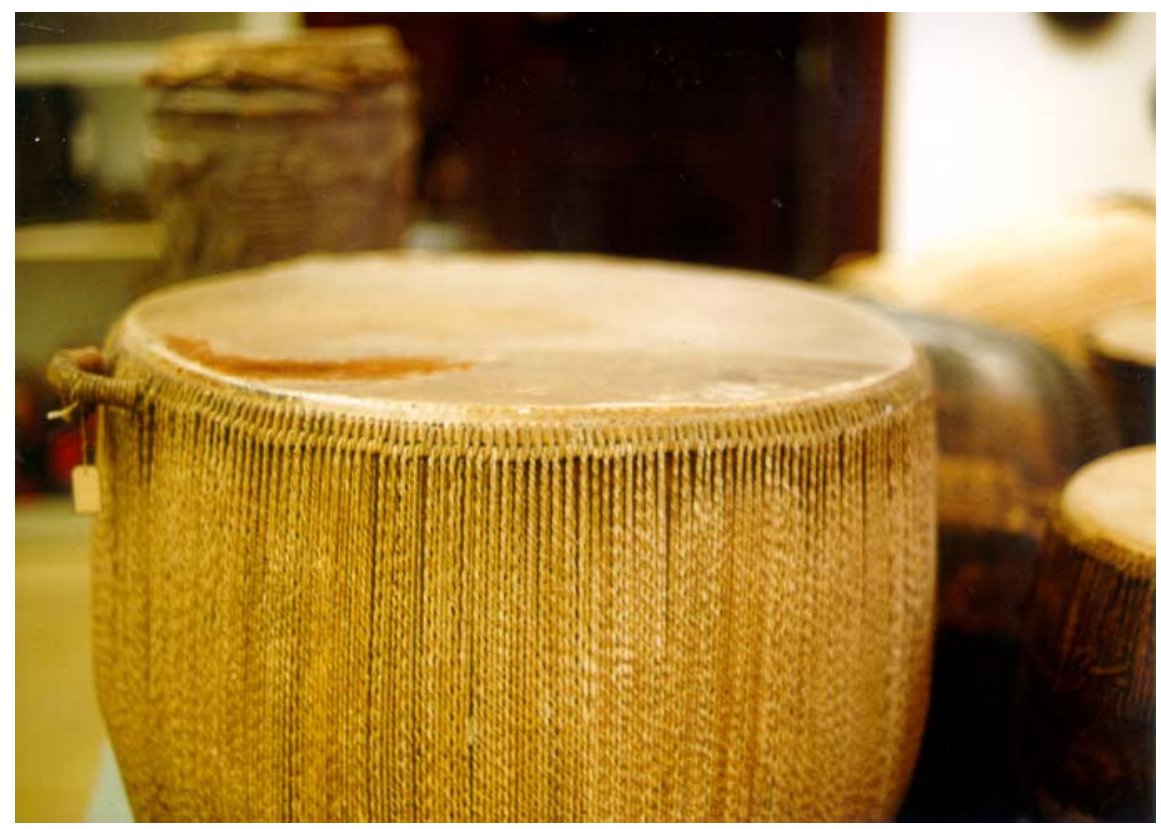




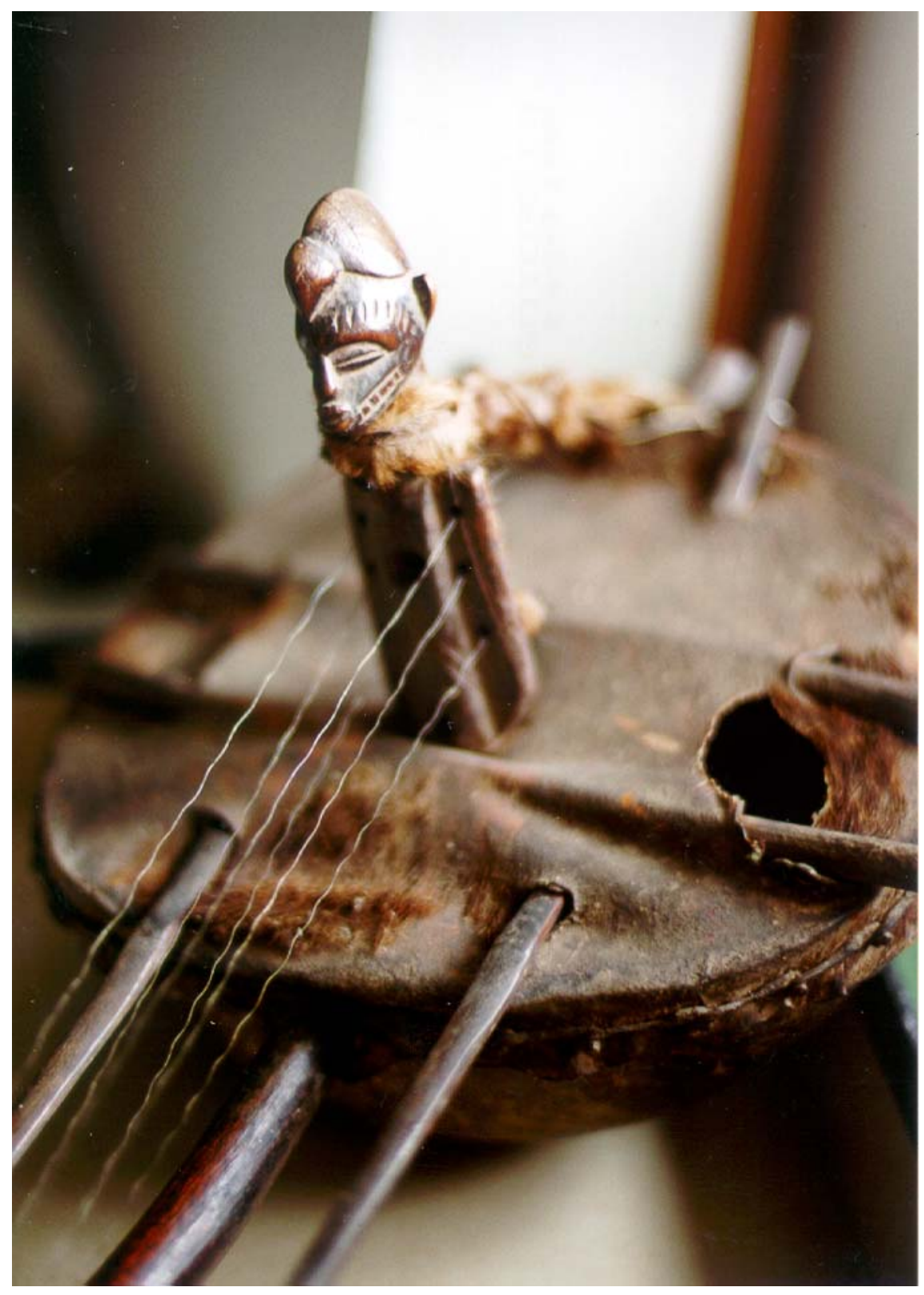

